\title{
Genome-wide DNA methylation can identify preterm birth- related genes in maternal blood
}

\section{Young-Ah You \\ EWHA Medical Research Institute

\author{
EWHA Medical Research Institute
} \\ Eun Jin Kwon}

\section{Han-Sung Hwang}

Konkuk University School of Medicine

\section{Suk-Joo Choi}

Samsung Medical Center

\section{Sae Kyung Choi}

Catholic University of Korea School of Medicine

Young Ju Kim ( $\nabla$ kkj@ewha.ac.kr)

https://orcid.org/0000-0002-3153-3008

\section{Research article}

Keywords: DNA methylation, maternal blood, VTRNA2-1, preterm birth, epigenetics

Posted Date: March 31st, 2020

DOI: https://doi.org/10.21203/rs.3.rs-20052/v1

License: (1) This work is licensed under a Creative Commons Attribution 4.0 International License. Read Full License

Version of Record: A version of this preprint was published at BMC Genomics on July 10th, 2021. See the published version at https://doi.org/10.1186/s12864-021-07865-y. 


\section{Abstract}

Background Preterm birth is associated with an increased risk of neonatal complications and death, as well as poor health and disease later in life. Epigenetics could contribute to the mechanism underlying preterm birth.

Results Genome-wide DNA methylation in whole blood cells from ten women was assessed using Illumina Infinium HumanMethylation450 BeadChips array. We identified 6,755 differentially methylated CpG sites between term and preterm birth. Although no differential methylation of these CpGs were found in correcting for multiple tests, seven VTRNA2-1 CpGs in promotor region of island were detected in top different methylation. We performed pyrosequencing validation with blood samples from the pregnant women. The methylation levels of VTRNA2-1 were either low (hypomethylated, $0-12.2 \%$ ) or high (hypermethylated, 32.6-50.8\%). Hypermethylation of VTRNA2-1 was associated with an increased risk of preterm birth after adjusting for maternal age, delivered season, parity and count of white blood cell. The mRNA expression of VTRNA2-1 was 0.51-fold lower in PTB delivered women compared with women with term deliveries.

Conclusion This study suggests that change of VTRNA2-1 methylation is related to PTB in maternal blood. Further elucidate to underlay mechanisms of preterm birth and affect to future systems biology studies to predict preterm birth.

\section{Background}

Despite the slight reduction in the overall rate of preterm births ( $<37$ weeks' gestation) globally, the rate of preterm birth (PTB) in Korea increased from $4.8 \%$ in 2008 to $7.8 \%$ in 2018 [1]. To date, clinicians and researchers have made great efforts to improve the identification of women at risk for PTB before its occurrence, as well as to develop therapeutics for its prevention. However, the early identification of PTB and therapy to mitigate its risk remain controversial [2-4].

PTB is associated with an increased risk of complications and neonatal death, as well as poor health and disease later in life [5-8]. Spontaneous PTB has a range of contributing risk factors, including infection, undernutrition, stress, and substance use [9], which are linked by two common pathways [10]. First, inflammatory and neuroendocrine pathways are activated in response to stress or stress-related behaviours, such as smoking [11], causing the upregulation of inflammatory cytokine production [11]. Second, cytokine-prostaglandin cascades are activated in response to infection [10]. Due to the involvement of inflammatory mechanisms in both pathways, previous studies investigating potential biomarkers for PTB have focused on inflammatory mediators $[12,13]$.

Genome-wide DNA methylation is implicated in the underlying mechanism of PTB and may provide a new approach for biomarker discovery $[14,15]$. The changes of DNA methylation in blood can be a reliable enough measure of inflammatory related condition [16]. Moreover, the ability to assess the epigenome has resulted in the identification of epigenetic signatures of the intrauterine environment, which are affected by body mass index (BMI), nutrition, medication, stress, and smoking for several years [17-23]. Many studies suggested that differentially methylated genes are involved in the genetic and environmental contributions to PTB and chronic disease risk. DNA methylation changes in the amnion or foetal tissue were determined to be partially involved in the physiological process of PTB and in foetal development. [24-26]. Thus, the evaluation of genes containing these differentially methylated sites may be useful to identify biological pathways involved in PTB, thereby facilitating the identification of clinically informative biomarkers for the prediction of PTB.

In this study, we investigated the DNA methylation profiles of maternal blood collected from pregnant women with term and preterm births. We also analysed the epigenetic modifications to determine the underlying mechanism of PTB.

\section{Results}

\section{Methylation array in the peripheral blood of women delivering at term and preterm}


A genome-wide analysis of DNA methylation was performed to search for candidate differentially methylated genes in maternal blood at the time of delivery. Of the 485,577 CpG sites tested, 6,755 sites significantly differed in DM $(p<0.05)$ between the two groups. However, because of the small sample size, we found no differential methylation of these CpGs after correcting for multiple testing. Next, 1,581 CpG sites on the island of the promoter regions were found (Table S1). Especially, seven VTRNA2-1 CpGs in the promoter were significantly hypermethylated in the PTB samples $(\mathrm{p}<0.05)($ Table 1$)$. In addition, these seven CpGs were all hypermethylated (range 25.0 to $55.1 \%, n=5$ ) or hypomethylated (range 2.6 to $14.1 \%, n=5$ ) in each sample (Figure S1).

Table 1

Differential methylation of seven CpG sites on VTRNA2-1 DNA islands in the maternal blood of women delivered at term and preterm using Illumina $450 \mathrm{~K}(\mathrm{n}=10)$.

\begin{tabular}{|c|c|c|c|c|c|c|c|c|c|}
\hline Target IDT & $\begin{array}{l}\text { Gene } \\
\text { symbol }\end{array}$ & Gene ID $\ddagger$ & CHR & $\begin{array}{l}\text { Functional } \\
\text { location }\end{array}$ & $\begin{array}{l}\text { Mean } \beta \\
\text { value in } \\
\text { term } \\
\text { samples } \\
(n=5)\end{array}$ & $\begin{array}{l}\text { Mean } \beta \\
\text { value in } \\
\text { preterm } \\
\text { samples } \\
(n=5)\end{array}$ & Difference* & $\begin{array}{l}\text { p- } \\
\text { value }^{2}\end{array}$ & FDR \\
\hline cg26328633 & $\begin{array}{l}\text { VTRNA2- } \\
1\end{array}$ & 100126299 & 5 & TSS200 & 0.125 & 0.520 & 0.395 & $\begin{array}{l}1.36 \mathrm{E}- \\
02\end{array}$ & 5.63 \\
\hline cg25340688 & $\begin{array}{l}\text { VTRNA2- } \\
1\end{array}$ & 100126299 & 5 & TSS200 & 0.121 & 0.508 & 0.387 & $\begin{array}{l}1.42 \mathrm{E}- \\
02\end{array}$ & 5.46 \\
\hline cg06536614 & $\begin{array}{l}\text { VTRNA2- } \\
1\end{array}$ & 100126299 & 5 & TSS200 & 0.129 & 0.492 & 0.363 & $\begin{array}{l}1.95 \mathrm{E}- \\
02\end{array}$ & 5.01 \\
\hline cg00124993 & $\begin{array}{l}\text { VTRNA2- } \\
1\end{array}$ & 100126299 & 5 & TSS200 & 0.114 & 0.471 & 0.357 & $\begin{array}{l}1.40 \mathrm{E}- \\
02\end{array}$ & 5.49 \\
\hline cg26896946 & $\begin{array}{l}\text { VTRNA2- } \\
1\end{array}$ & 100126299 & 5 & TSS200 & 0.192 & 0.503 & 0.311 & $\begin{array}{l}1.29 \mathrm{E}- \\
02\end{array}$ & 5.65 \\
\hline cg04481923 & $\begin{array}{l}\text { VTRNA2- } \\
1\end{array}$ & 100126299 & 5 & 1stExon;3'UTR & 0.122 & 0.389 & 0.0267 & $\begin{array}{l}1.52 \mathrm{E}- \\
02\end{array}$ & 5.47 \\
\hline $\operatorname{cg} 18678645$ & $\begin{array}{l}\text { VTRNA2- } \\
1\end{array}$ & 100126299 & 5 & TSS200 & 0.115 & 0.376 & 0.261 & $\begin{array}{l}5.05 \mathrm{E}- \\
03\end{array}$ & 7.50 \\
\hline \multicolumn{10}{|c|}{$\begin{array}{l}\text { tldentifies the probe name, } ¥ \text { GenBank gene ID was updated in May } 2016 . p<0.05 \text {. * Difference between mean } \beta \text { values of } \\
\text { preterm birth and term. The false-discovery rate (FDR) was controlled using the Benjamini-Hochberg correction. }\end{array}$} \\
\hline
\end{tabular}

\section{Validation Of Vtrna2-1 Methylation}

Subsequently, we conducted pyrosequencing to investigate the association between VTRNA2-1 methylation (cg04481923) and PTB in maternal blood samples (term, $n=39$; preterm, $n=43$ ). The primer sets for VTRNA2-1 CpG sites were designed using PSQ Assay Design (Biotage AB, Uppsala, Sweden). Table 2 shows the clinical characteristics of the 82 pregnant women. Maternal age ranged from 27-39 years in women with term deliveries and from 22-43 years in women with PTB. Overall, the mean gestational age and BMI of women with term births were 39 weeks, 4 days, and 26.0, respectively, and that of women with PTB were 29 weeks, 1 day, and 23.8, respectively. The presence of labour in C-section did not differ significantly between the term and preterm groups by the chi-square test $(P>0.05)$. Table 3 shows the DNA methylation levels of three CpGs on VTRNA2-1 after pyrosequencing; two CpGs differed significantly between pregnant women with term and preterm births $(p<0.05)$. These three CpG sites of VTRNA2-1 identified in each sample were concordant with hypomethylation (range $0.0-12.2 \%, n=28$ ) or hypermethylation (range $32.6-50.8 \%, n=54$ ) (Fig. 1a). In addition, preterm delivered women were 
more likely to exhibit hypermethylation (>30\%) of VTRANA2-1 than term delivered women $(p=0.06$, Fig. $1 \mathrm{~b})$. To explore the association between methylation status and mRNA expression, the mRNA expression of VTRNA2-1 in maternal blood was analysed. The relative expression level of VTRNA2-1 was 0.51-fold lower $(p<0.05)$ in PTB delivered women compared with women with term deliveries (Fig. 1c). 
Table 2

Clinical characteristics of the study groups.

\begin{tabular}{|c|c|c|c|}
\hline & Term $(\geq 37, n=39)$ & Preterm $(<37, n=43)$ & p-value \\
\hline & Mean \pm SD & Mean \pm SD & \\
\hline Maternal age & $31.7 \pm 2.8$ & $30.9 \pm 4.6$ & 0.418 \\
\hline BMI at delivery & $25.9 \pm 3.3$ & $24.1 \pm 4.2$ & $0.037^{a}$ \\
\hline Gravidity & & & 0.144 \\
\hline 0 & $16(41.0)$ & $15(34.9)$ & \\
\hline 1 & $23(59.0)$ & $25(65.1)$ & \\
\hline Parity & & & 0.634 \\
\hline Nulliparous & $22(56.4)$ & $22(51.2)$ & \\
\hline Multiparous & $17(43.6)$ & $18(48.8)$ & \\
\hline Delivery season & & & $0.021^{\star}$ \\
\hline Spring, n (\%) & $5(12.8)$ & $12(27.9)$ & \\
\hline Summer, n (\%) & $3(7.7)$ & $11(25.6)$ & \\
\hline Autumn, n (\%) & $19(48.7)$ & $13(30.2)$ & \\
\hline Winter, n (\%) & $12(30.8)$ & $7(16.3)$ & \\
\hline Mode of delivery & & & 0.366 \\
\hline Vaginal, n (\%) & $24(62.5)$ & $24(55.8)$ & \\
\hline C-section, n (\%) & $15(37.5)$ & $19(44.2)$ & \\
\hline Education & & & 0.096 \\
\hline Below high school & $8(20.5)$ & $13(44.8)$ & \\
\hline College or more & $31(79.5)$ & $16(45.2)$ & \\
\hline Gestational age & $39.4 \pm 1.0$ & $29.1 \pm 2.8$ & $<0.001^{a}$ \\
\hline White blood cell, (cells/ $\mu \mathrm{L}$ ) & $10101.8 \pm 3004.8$ & $12209.5 \pm 3825.8$ & 0.008 \\
\hline Mycoplasma & & & 0.702 \\
\hline Positive, n (\%) & $2(2.4)$ & $13(37.1)$ & \\
\hline Negative, n (\%) & 35 (89.7) & 34 (91.9) & \\
\hline Ureaplasma & & & 0.037 \\
\hline Positive, n (\%) & $0(0.0)$ & $8(21.6)$ & \\
\hline Negative, n (\%) & $37(94.9)$ & $22(78.4)$ & \\
\hline Chorioamnionitis & & & 0.002 \\
\hline Positive, n (\%) & $0(0.0)$ & $1(30.2)$ & \\
\hline
\end{tabular}




\begin{tabular}{|c|c|c|c|}
\hline & Term $(\geq 37, n=39)$ & Preterm $(<37, \mathrm{n}=43)$ & p-value \\
\hline & Mean \pm SD & Mean \pm SD & \\
\hline Negative, n (\%) & 37 (94.9) & $13(66.7)$ & \\
\hline Birth weight & $3310.5 \pm 394.7$ & $1385.7 \pm 504.1$ & $<0.001^{\mathrm{a}}$ \\
\hline Sex & & & 0.654 \\
\hline Male, n (\%) & $20(50.0)$ & $22(55.0)$ & \\
\hline Female, n (\%) & $20(50.0)$ & $18(45.0)$ & \\
\hline Apgar 1 min & $9.5 \pm 0.8$ & $5.9 \pm 2.4$ & $<0.001^{\mathrm{a}}$ \\
\hline Apgar 5 min & $9.9 \pm 0.2$ & $7.5 \pm 2.1$ & $<0.001^{a}$ \\
\hline
\end{tabular}

Table 3

Comparison of specific DNA methylation sites between women with term and preterm births after pyrosequencing.

\begin{tabular}{|c|c|c|c|c|}
\hline Variable & Target ID + of differential methylated site & $\begin{array}{l}\text { Term } \\
(n=39)\end{array}$ & $\begin{array}{l}\text { Preterm } \\
(n=43)\end{array}$ & p-value \\
\hline VTRNA2-1_pos1 & $\operatorname{cg} 04481923$ & $25.8 \pm 20.9$ & $33.9 \pm 18.6$ & 0.065 \\
\hline VTRNA2-1_pos2 & & $26.3 \pm 22.2$ & $35.2 \pm 19.5$ & $0.045^{\mathrm{a}}$ \\
\hline VTRNA2-1_pos3 & & $27.4 \pm 22.3$ & $36.4 \pm 19.8$ & $0.026^{a}$ \\
\hline
\end{tabular}

\section{Preterm Birth-related Dna Methylation Changes In Maternal Blood}

Table 4 shows the association between DNA methylation sites and PTB by logistic regression analysis. We analysed the association between DNA methylation changes in VTRNA2-1 and PTB. Based on the $\beta$ values of VTRNA2-1, the patients were divided into the following two groups: hypomethylation and hypermethylation. Hypermethylation of VTRNA2-1 was associated with a significantly increased risk of PTB compared with hypomethylation of VTRNA2-1 (adjusted OR $=3.358,95 \%$ $\mathrm{Cl}$ 1.114-10.126). Interestingly, younger women were more likely to have preterm deliveries in the VTRNA2-1 hypomethylation group $(p<0.05$, Table 5). Moreover, women with preterm deliveries in the hypermethylation group had lower BMls and higher WBC counts, and they were more likely to deliver during spring or summer than autumn or winter $(p<0.05)$. 
Table 4

Logistic regression analysis of the association between specific DNA methylation sites and preterm births $(n=82)$.

\begin{tabular}{|c|c|c|c|c|c|}
\hline Methylation & $\beta$-value & SE & Odds ratio & $95 \% \mathrm{Cl}$ & p-value \\
\hline Intercept & 1.656 & 2.474 & 5.241 & & 0.503 \\
\hline Age & -0.083 & 0.069 & 0.921 & $0.804-1.000$ & 0.235 \\
\hline Season & -0.583 & 0.254 & 0.558 & $0.340-0.917$ & 0.021 \\
\hline Parity & 0.368 & 0.316 & 1.444 & $0.778-2.682$ & 0.244 \\
\hline VTRNA2-1* & 1.211 & 0.563 & 3.358 & $1.114-10.126$ & 0.031 \\
\hline WBC count & 0.000 & 0.000 & 1.000 & $1.000-1.000$ & 0.085 \\
\hline
\end{tabular}


Table 5

Clinical characteristics of VTRNA2-1 hypo- and hyper-methylation groups.

\begin{tabular}{|c|c|c|c|c|c|c|}
\hline & \multicolumn{2}{|c|}{ Hypomethylation } & \multicolumn{3}{|c|}{ Hypermethylation } & \multirow[b]{2}{*}{$p$-value } \\
\hline & $\begin{array}{l}\text { Term } \\
(n=17)\end{array}$ & $\begin{array}{l}\text { Preterm } \\
(\mathrm{n}=11)\end{array}$ & $\mathrm{p}$-value & $\begin{array}{l}\text { Term } \\
(n=22)\end{array}$ & $\begin{array}{l}\text { Preterm } \\
(\mathrm{n}=32)\end{array}$ & \\
\hline Maternal age & $31.7 \pm 2.7$ & $28.2 \pm 2.5$ & 0.002 & $31.7 \pm 3.1$ & $31.9 \pm 4.7$ & 0.812 \\
\hline BMI & $26.3 \pm 3.3$ & $24.5 \pm 5.4$ & 0.320 & $25.8 \pm 3.3$ & $23.5 \pm 3.4$ & 0.024 \\
\hline Gravidity* & & & 0.954 & & & 0.412 \\
\hline 0 & $6(35.3)$ & $4(36.4)$ & & $10(45.5)$ & $11(34.4)$ & \\
\hline 1 & $11(64.7)$ & $7(63.6)$ & & $12(54.5)$ & $21(65.6)$ & \\
\hline Parity* & & & 0.761 & & & 0.026 \\
\hline Nulliparous & $9(52.9)$ & $5(45.5)$ & & $13(59.1)$ & $17(53.1)$ & \\
\hline Multiparous & $8(47.1)$ & $6(54.5)$ & & $9(40.9)$ & $15(46.9)$ & \\
\hline Delivery season* & & & 0.775 & & & 0.009 \\
\hline Spring, n (\%) & $4(23.5)$ & $4(36.4)$ & & $1(4.5)$ & $8(25.0)$ & \\
\hline Summer, n (\%) & $1(5.9)$ & $0(0.0)$ & & $2(9.1)$ & $11(34.4)$ & \\
\hline Autumn, n (\%) & $9(52.9)$ & $5(45.5)$ & & $10(45.5)$ & $8(25.0)$ & \\
\hline Winter, $n(\%)$ & $3(17.6)$ & $2(18.2)$ & & $9(40.9)$ & $5(15.6)$ & \\
\hline Mode of delivery* & & & 0.435 & & & 0.264 \\
\hline Vaginal, n (\%) & $9(52.9)$ & $8(72.7)$ & & $15(68.2)$ & $16(50.0)$ & \\
\hline C-section, n (\%) & $8(47.1)$ & $3(27.3)$ & & $7(31.8)$ & $16(50.0)$ & \\
\hline Education & & & 0.417 & & & 0.226 \\
\hline Below high school & $3(17.6)$ & $3(37.5)$ & & $5(22.7)$ & $10(47.6)$ & \\
\hline Above college & $14(82.4)$ & $5(62.5)$ & & $17(77.3)$ & $11(52.4)$ & \\
\hline Gestational age & $39.4 \pm 1.0$ & $29.3 \pm 2.4$ & $<0.001$ & $39.4 \pm 1.4$ & $29.1 \pm 2.9$ & $<0.001$ \\
\hline WBC $\left(x 10^{3}\right)$ & $10.3 \pm 3.3$ & $11.9 \pm 3.0$ & 0.218 & $9.9 \pm 2.9$ & $12.3 \pm 4.0$ & 0.028 \\
\hline Ureaplasma* & & & 0.005 & & & 0.002 \\
\hline Negative & 15 (88.2) & $4(36.4)$ & & $22(100.0)$ & $18(56.3)$ & \\
\hline Positive & $0(0.0)$ & $5(45.5)$ & & $0(0.0)$ & $8(25.0)$ & \\
\hline \multicolumn{7}{|l|}{ Birth outcome } \\
\hline Body weight (kg) & $3.5 \pm 0.4$ & $1.2 \pm 0.3$ & $<0.001$ & $3.2 \pm 0.3$ & $1.4 \pm 0.5$ & $<0.001$ \\
\hline Sex* & & & 0.934 & & & 0.783 \\
\hline Male, n (\%) & $9(52.9)$ & $6(54.5)$ & & $11(40.0)$ & $18(56.3)$ & \\
\hline Female, n (\%) & $8(47.1)$ & $5(45.5)$ & & $11(60.0)$ & $14(43.8)$ & \\
\hline
\end{tabular}




\begin{tabular}{|c|c|c|c|c|c|c|}
\hline \multirow[b]{2}{*}{ Apgar $1 \mathrm{~min}$} & \multicolumn{2}{|c|}{ Hypomethylation } & \multicolumn{3}{|c|}{ Hypermethylation } & \multirow[b]{2}{*}{$<0.001$} \\
\hline & $9.3 \pm 0.9$ & $6.3 \pm 1.8$ & $<0.001$ & $9.7 \pm 0.5$ & $5.7 \pm 2.5$ & \\
\hline Apgar 5 min & $9.9 \pm 0.3$ & $7.8 \pm 1.6$ & $<0.001$ & $10.0 \pm 0.0$ & $7.4 \pm 2.2$ & $<0.001$ \\
\hline
\end{tabular}

\section{Discussion}

We examined PTB-related DNA methylation changes using genome-wide methylation analysis in maternal blood. Although we found no differential methylation of these $\mathrm{CpGs}$ after correcting for multiple tests, seven VTRNA2-1 CpGs in the promoters were differently methylated in blood samples of term compared with preterm delivered women. In addition, VTRNA2-1 hypermethylation was associated with increased risk of PTB (through pyrosequencing), and negatively correlated with gene expression. This result may help elucidate the underlying mechanism of PTB and affect future efforts by systems biologists to predict PTB.

PTB remains the leading cause of childhood morbidity and death. Its aetiology remains unclear; however, significant advancements have been made in the identification of biomarkers to predict high-risk pregnancies resulting in PTB. Indeed, in the last decade, DNA methylation has emerged as an important player of both physiological and pathophysiological responses. Studies have suggested that maternal factors, including pre-pregnancy BMI [21], nutrition [22], smoking during pregnancy [27], and socioeconomic status [11] increase the risk of PTB, and DNA methylation has partially explained many of these factors [17-23]. In this study, we found an association among maternal BMI, delivery season, and WBC count with PTB; however, these factors did not influence the DNA methylation levels in maternal blood.

VTRNA2-1 was determined to have significant DM sites in various regions and is associated with several diseases [28-30]. VTRNA2-1 is a putative tumour suppressor and modulator of innate immunity [28]. Although few studies have studied the relationship between VTRNA2-1 and PTB, its hypermethylation is associated with poor outcomes in patients with human small cell lung cancer and acute myeloid leukaemia $[29,30]$. The expression of VTRNA2-1 negatively correlated with methylation levels in this study. A recent study showed that the inhibition of VTRNA2-1 led to the activation of the cellular antiviral response pathway involving protein kinase-R (PKR) [31, 32]. PKR activation can be induced by various stressful stimuli, such as cytotoxic cytokines, growth factor deprivation, and DNA damage [33]. Therefore, we hypothesise that the association between VTRNA2-1 methylation and PTB will result in PKR activation due to stressful stimuli.

One study reported that the methylation level of VTRNA2-1 was associated with the season of conception and maternal nutrition in rural Gambia [28]. Specifically, the authors reported that women had differing nutrition in the dry and rainy seasons during pre-conception. However, although our VTRNA2-1 methylation data were associated with delivery season, it is difficult to explain the relationship between PTB and methylation changes by season. In our study, the methylation of VTRNA2-1 was divided into two levels: low (hypomethylation, 0-12.5\%) and high (hypermethylation, 31.7-54.2\%). Younger maternal age was associated with PTB in the VTRNA2-1 hypomethylation group. Moreover, in the hypermethylation group, low BMI, higher WBC counts, and delivery season were associated with PTB.

We acknowledge several limitations of our study, including the paucity of the clinical and demographic data of our samples, such as smoking, alcohol consumption, and the use of other drugs or medications. We were only able to demonstrate a correlation between methylation and expression at a small subset of $\mathrm{CpG}$ sites and in a small sample size due to the limited availability of RNA from maternal blood samples. Finally, when we analysed the VTRNA2-1 methylation level using a simple linear regression model that included the cell composition percentages as covariates, the VTRNA2-1 methylation level was not affected by cell composition $(P>0.05)$. However, we did not consider DNA methylation status according to cellular heterogeneity because we did not sort blood cell type at the time of blood collection. 


\section{Conclusions}

This study suggests the genome-wide DNA methylation in whole blood cells could be associated with preterm birth. Interestingly, our results showed the potential of VTRNA2-1 methylation analysis related to PTB in maternal blood. Moreover, this result may help to elucidate the mechanisms of PTB. Further studies are warranted to confirm the DNA methylation changes of VTRNA2-1 in a broader global population according to cell type.

\section{Methods}

\section{Study population}

We conducted a case-control study of 10 pregnant women with term $(n=5)$ and preterm deliveries $(n=5)$ at Ewha Womans University Mokdong Hospital (Seoul, Korea) to screen changes in methylation level. Maternal peripheral blood samples from participants were collected at the time of delivery, and the birth outcome was followed (Table S2). DNA methylation was measured using the Illumina Human Methylation 450 BeadChip. To validate the differential methylation (DM) levels, 80 blood samples from women with term $(n=39)$ and preterm $(n=43)$ births were examined. All participants gave informed consent, and the study was approved by the Institutional Review Board of Ewha Womans University Mokdong Hospital (Certificate No. EUMC 2014-06-010-003, Samsung Medical Center (SMC 2014-06-094-003), Konkuk University Medical Center (KUH1040034), and Seoul St. Mary's Hospital (KC14TIMI0591). Women with multiple births, major birth defects, and pregnancy complications were excluded. Gestational age was determined using the first day of the last menstrual period and ultrasound examination.

\section{DNA preparation and genome-wide DNA methylation analysis}

Maternal blood was collected in EDTA tubes, and the plasma was separated and stored at $-80^{\circ} \mathrm{C}$. Genomic DNA was extracted from blood samples using the QIAGEN Mini Kit (QIAGEN, Valencia, CA, USA) following the manufacturer's protocol. The quality of the extracted DNA was evaluated using agarose gel electrophoresis. To analyse DNA methylation, $700 \mathrm{ng}$ genomic DNA was bisulphite-converted using the Zymo EZ DNA Methylation Kit (Zymo Research, Irvine, CA, USA), amplified, fragmented, and hybridised to the Illumina Infinium HumanMethylation450 BeadChip (Illumina, San Diego, CA, USA) following the manufacturer's protocol. After washing, the BeadChips were scanned with the HiScan SQ System (Illumina). Scanned images were processed to determine the signal intensity and $\beta$-values were calculated using Genome Studio software (Illumina). The $\beta$-value, as defined below, was used to measure methylation levels on a scale from 0 to 1 :

$$
\beta=\frac{\operatorname{Max}(\text { Signal B.0) }}{\text { Max (Signal A.0 })+ \text { Max }(\text { Signal B.0 })+100}
$$

$\operatorname{Max}($ Signal $A, 0)$ indicates the signal intensity of the unmethylated allele, and Max (Signal $B, 0)$ indicates the signal intensity of the methylated allele. A constant bias of 100 was added to regularise the $\beta$-value. The $\beta$-values were calculated; normalisation, filtration, and statistical analyses were performed using GeneSpring ver. 7.3 (Agilent Technologies, Santa Clara, CA, USA). The normalised $\beta$-value of all $\mathrm{CpG}$ sites in the two groups (term vs. preterm) were statistically evaluated using Welch's t-test $(p<0.05)$, and the $p$-values were adjusted for the number of hypothesis tests performed using the falsediscovery rate (FDR). The FDR was controlled using the Benjamini-Hochberg correction.

\section{DM analysis by pyrosequencing}

DM levels measured by the genome-wide methylation array were validated in maternal term $(n=39)$ and preterm $(n=43)$ blood by pyrosequencing using the PyroMark PCR Kit (QIAGEN). The cg04072545 and cg04481923 sites were amplified using a primer set designed using PSQ Assay Design software (Biotage AB, Uppsala, Sweden) (Table S3). The methodological details for pyrosequencing are reported in our previous study [34].

RNA isolation and quantitative real-time polymerase chain reaction 
Total RNA from maternal blood was extracted using the Easy-BLUE ${ }^{\text {TM }}$ Kit (iNtRON Biotechnology, Sungnam, Korea) according to the manufacturer's instructions. RNA was reverse transcribed using $1 \mu \mathrm{g}$ total RNA in a $25 \mu \mathrm{L}$ reaction mixture containing $1 \mu \mathrm{L} 10 \mathrm{pM}$ oligonucleotide primer, $5 \mu \mathrm{L} 10 \times$ reverse transcription buffer, $5 \mu \mathrm{L} 2.5 \mathrm{mM}$ dNTPs, $1 \mu \mathrm{L} 20 \mathrm{U}$ RNase inhibitor, and $1 \mu \mathrm{L} 200 \mathrm{U}$ Moloney murine leukaemia virus reverse transcriptase (M-MLV RT) (Promega, Madison, WI, USA) for $60 \mathrm{~min}$ at $42{ }^{\circ} \mathrm{C}$. Real-time quantitative-polymerase chain reaction (qPCR) was performed using synthesised cDNA as a template, genespecific primers (VTRNA2-1), and Power SYBR Green PCR Master Mix (Applied Biosystems, Foster City, California, USA). The reactions (including the no-template controls) were run in duplicate on the ABI PRISM 7000 sequence detection system (Applied BioSystems) using glyceraldehyde-3-phosphate dehydrogenase (GAPDH) as an internal reference for normalisation of target gene mRNA expression. The PCR conditions were as follows: denaturation at $95^{\circ} \mathrm{C}$ for $30 \mathrm{~s}, 40$ cycles of denaturation at $95^{\circ} \mathrm{C}$ for $15 \mathrm{~s}$, and annealing/extension at $60^{\circ} \mathrm{C}$ for $1 \mathrm{~min}$. We tested primer specificity by RT-PCR and confirmed it using melting (dissociation) curve analysis. Comparative quantification of each target gene was performed based on the cycle threshold (CT), which was normalised against the CT of GAPDH using the $\triangle \triangle \mathrm{CT}$ method. Data are presented as the fold change between groups as the mean \pm standard error of the mean (SEM). The primer sets and melting temperature (Tm) for qPCR are described in Table S4.

\section{Statistical analysis}

The basic characteristics of the study groups were compared using Student's t-test for continuous variables and the chisquare test for categorical variables. After pyrosequencing, the DNA methylation levels between the two groups were compared using the Mann-Whitney U-test. The DNA methylation levels of VTRNA2-1 were analysed as two separate groups: hypomethylation (0-12.5\%) and hypermethylation (31.7-54.2\%) groups by the rank of methylation level. To explore the association between VTRNA2-1 methylation level and PTB, multiple logistic regression was conducted, controlling for maternal age, parity, season, and white blood cell (WBC) count. In addition, the clinical characteristics of the VTRNA2-1 hypoand hypermethylation groups were analysed using Student's t-test and the chi-square test. All analyses were two-tailed, and a p-value $<0.05$ was considered statistically significant. All statistical analyses were performed using SPSS software ver. 21.0 (IBM, Armonk, NY, USA).

\section{Declarations}

\section{Ethics approval and consent to participate}

All participants gave informed consent, and the study was approved by the Institutional Review Board of Ewha Womans University Mokdong Hospital (Certificate No. EUMC 2014-06-010-003, Samsung Medical Center (SMC 2014-06-094-003), Konkuk University Medical Center (KUH1040034), and Seoul St. Mary's Hospital (KC14TIMI0591).

\section{Consent for publication}

Not applicable.

\section{Availability of data and materials}

\section{Competing interests}

The authors declare that they have no competing interest.

\section{Funding}

This study was supported by the Ministry of Health \& Welfare of the Republic of Korea (grant numbers: HI14C0306 and HI18C0378) through the Korea Health Industry Development Institute.

\section{Author's Contribution}


YAY and KYJ designed the study and wrote the manuscript. YAY and KEJ performed the experiments. YAY, KEJ, and KYJ performed the research and analysed the data. HHS, CSJ, and CSK participated in data analysis. All authors interpreted and discussed the data, reviewed and revised the manuscript, and approved the final version of the manuscript.

\section{References}

1. Korea National Birthplace Survey. Korean National Statistical Office 2019.

2. Raju TN, Higgins RD, Stark AR, Leveno KJ. Optimizing care and outcome for late-preterm (near-term) infants: a summary of the workshop sponsored by the National Institute of Child Health and Human Development. Pediatrics. 2006;118:12071214.

3. Ananth CV, Vintzileos AM. Epidemiology of preterm birth and its clinical subtypes. J Matern Fetal Neonatal Med. 2006;19:773-782.

4. Hwang HS, Na SH, Hur SE, Lee SA, Lee KA, Cho GJ, et al. Practice patterns in the management of threatened preterm labor in Korea: a multicenter retrospective study. Obstet Gynecol Sci. 2015;58:203-209.

5. Villar J, Papageorghiou AT, Pang R, Ohuma EO, Cheikh Ismail L, Barros FC, et al. The likeness of fetal growth and newborn size across non-isolated populations in the INTERGROWTH-2 $1^{\text {st }}$ Project: The Fetal Growth Longitudinal Study and Newborn Cross-Sectional Study. Lancet Diabetes Endocrinol. 2014;2:781-792.

6. Beck S, Wojdyla D, Say L, Betran AP, Merialdi M, Requejo JH, et al. The worldwide incidence of preterm birth: A systematic review of maternal mortality and morbidity. Bull World Health Organ. 2010;88:31-38.

7. Yuan W, Basso O, Sorensen HT, Olsen J. Indicators of fetal growth and infectious disease in childhood-A birth cohort with hospitalization as outcome. Eur J Epidemiol. 2001;17:829-834.

8. Bhutta AT, Cleves MA, Casey PH, Cradock MM. Anand, K.J. Cognitive and behavioral outcomes of school-aged children who were born preterm: A meta-analysis. JAMA. 2002; 288:728-737.

9. Blencowe H, Cousens S, Chou D, Oestergaard M, Say L, Moller AB, et al.; Born Too Soon Preterm Birth Action Group Born too soon: The global epidemiology of 15 million preterm births. Reprod Health 2013;10(Suppl 1):S2.

10. Behrman RE, Butler AS. Preterm Birth: Causes, Consequences, and Prevention. The National Academies Press; 2007.

11. Menon R. Spontaneous preterm birth, a clinical dilemma: etiologic, pathophysiologic and genetic heterogeneities and racial disparity. Acta Obstet Gynecol Scand. 2008;87: 590-600.

12. Menon R, Conneely KN, Smith A. DNA methylation: An epigenetic risk factor in preterm birth. Reprod Sci. 2012;19:6-13.

13. Rubens CE, Sadovsky Y, Muglia L, Gravett MG, Lackritz E, Gravett C. Prevention of preterm birth: Harnessing science to address the global epidemic. Sci Transl Medicine 2014;6:262sr5.

14. Knight AK, Smith AK. Epigenetic biomarkers of preterm birth and its risk factors. Genes (Basel). 2016;7:pii: E15.

15. Parets SE, Conneely KN, Kilaru V, Fortunato SJ, Syed TA, Saade G, et al. DNA Methylation associated with early spontaneous preterm birth and gestational age. Plos one. 2013;8:e67489.

16. Rogac M, Peterlin B. Epigenetic Signature of Chronic Maternal Stress Load During Pregnancy Might be a Potential Biomarker for Spontaneous Preterm Birth. Balkan J Med Genet. 2018;21:27-33.

17. Stroud LR, Papandonatos GD, Rodriguez D, Meaghan M, Salisbury AM, Phipps MG, et al. Maternal smoking during pregnancy and infant stress response: Test of a prenatal programming hypothesis. Psychoneuroendocrinology. 2014;48:29-40.

18. Vidal AC, Benjamin Neelon SE, Liu Y, Tuli AM, Fuemmeler BF, Hoyo C,et al. Maternal stress, preterm birth, and DNA methylation at imprint regulatory sequences in humans. Genet Epigenet. 2014;6:37-44.

19. Simpkin AJ, Suderman M, Gaunt TR, Lyttleton O, McArdle WL, Ring SM, et al. Longitudinal analysis of DNA methylation associated with birth weight and gestational age. Hum Mol Genet. 2015;24:3752-3763.

20. Smith AK1, Conneely KN, Newport DJ, Kilaru V, Schroeder JW, Pennell PB, et al. Prenatal antiepileptic exposure associates with neonatal DNA methylation differences. Epigenetics Off J DNA Methylation Soc. 2012;7:458-463.

Page 12/14 
21. Sharp GC, Lawlor DA, Richmond RC, Fraser A, Simpkin A, Suderman M, et al. Maternal pre-pregnancy BMI and gestational weight gain, offspring DNA methylation and later offspring adiposity: Findings from the Avon Longitudinal Study of Parents and Children. Int J Epidemiol. 2015;44:1288-1304.

22. Shenker NS, Polidoro S, van Veldhoven K, Sacerdote C, Ricceri F, Birrell MA, et al. Epigenome-wide association study in the European Prospective Investigation into Cancer and Nutrition (EPIC-Turin) identifies novel genetic loci associated with smoking. Hum Mol Genet. 2013;22:843-851.

23. Soubry A, Murphy S, Huang Z, Murtha A, Schildkraut J, Jirtle R, et al. The effects of depression and use of antidepressive medicines during pregnancy on the methylation status of the IGF2 imprinted control regions in the offspring. Clin Epigenetics 2011;3: 2.

24. Kim J, Pitlick MM, Christine PJ, Schaefer AR, Saleme C, Comas B, et Genome-wide analysis of DNA methylation in human amnion. Scientific World Journal. 2013;2013:678156.

25. Han Z, Mulla S, Beyene J, Liao G, McDonald SD, Knowledge Synthesis Group. Maternal underweight and the risk of preterm birth and low birth weight: a systematic review and meta-analyses. Int J Epidemiol. 2011;40:65-101.

26. Eckmann-Scholz C, Bens J, Kolarova J, Schneppenheim S, Caliebe A, Heidemann, von Kaisenberg C, et al. DNAmethylation profiling of fetal tissues reveals marked epigenetic differences between chorionic and amniotic samples. Plos one. 2012;7: e39014.

27. Aliyu MH, Lynch O, Wilson RE, Alio AP, Kristensen S, Marty PJ, et al. Association between tobacco use in pregnancy and placenta-associated syndromes: A population-based study. Arch Gynecol Obstet. 2011;283:729-734.

28. Silver MJ, Kessler NJ, Hennig BJ, Dominguez-Salas P, Laritsky E, Baker MS, et al. Independent genome-wide screens identify the tumor suppressor VTRNA2-1 as a human epiallele responsive to periconceptional environment. Genome Biol. $2015 ; 16: 118$.

29. Cao J, Song Y, Bi N, Shen J, Liu W, Fan J, et al. DNA methylation-mediated repression of miR-886-3p predicts poor outcome of human small cell lung cancer. Cancer Res. 2013;73:3326-3335.

30. Treppendahl MB, Qiu X, Søgaard A, Yang X, Nandrup-Bus C, Hother C, et al. Allelic methylation levels of the noncoding VTRNA2-1 located on chromosome 5q31.1 predict outcome in AML. Blood. 2012;119:206-216.

31. Lee Kim, Kunkeaw N, Jeon SH, Lee I, Johnson BH, Kang GY, et al. Precursor miR-886, a novel noncoding RNA repressed in cancer, associates with PKR and modulates its activity. RNA. 2011;17:1076-1089.

32. Berger W, Steiner E, Grusch M, Elbling L, Micksche M. Vaults and the major vault protein: novel roles in signal pathway regulation and immunity. Cell Mol Life Sci. 2009;66:43-61.

33. García MA. Meurs EF, Esteban M. The dsRNA protein kinase PKR: virus and cell control. Biochimie. 2007;89:799-811.

34. Yoo JY, Lee S, Lee HA, Park H, Park YJ, Ha EH, et al. Can proopiomelanocortin methylation be used as an early predictor of metabolic syndrome? Diabetes Care 2014;37:734-739.

\section{Figures}



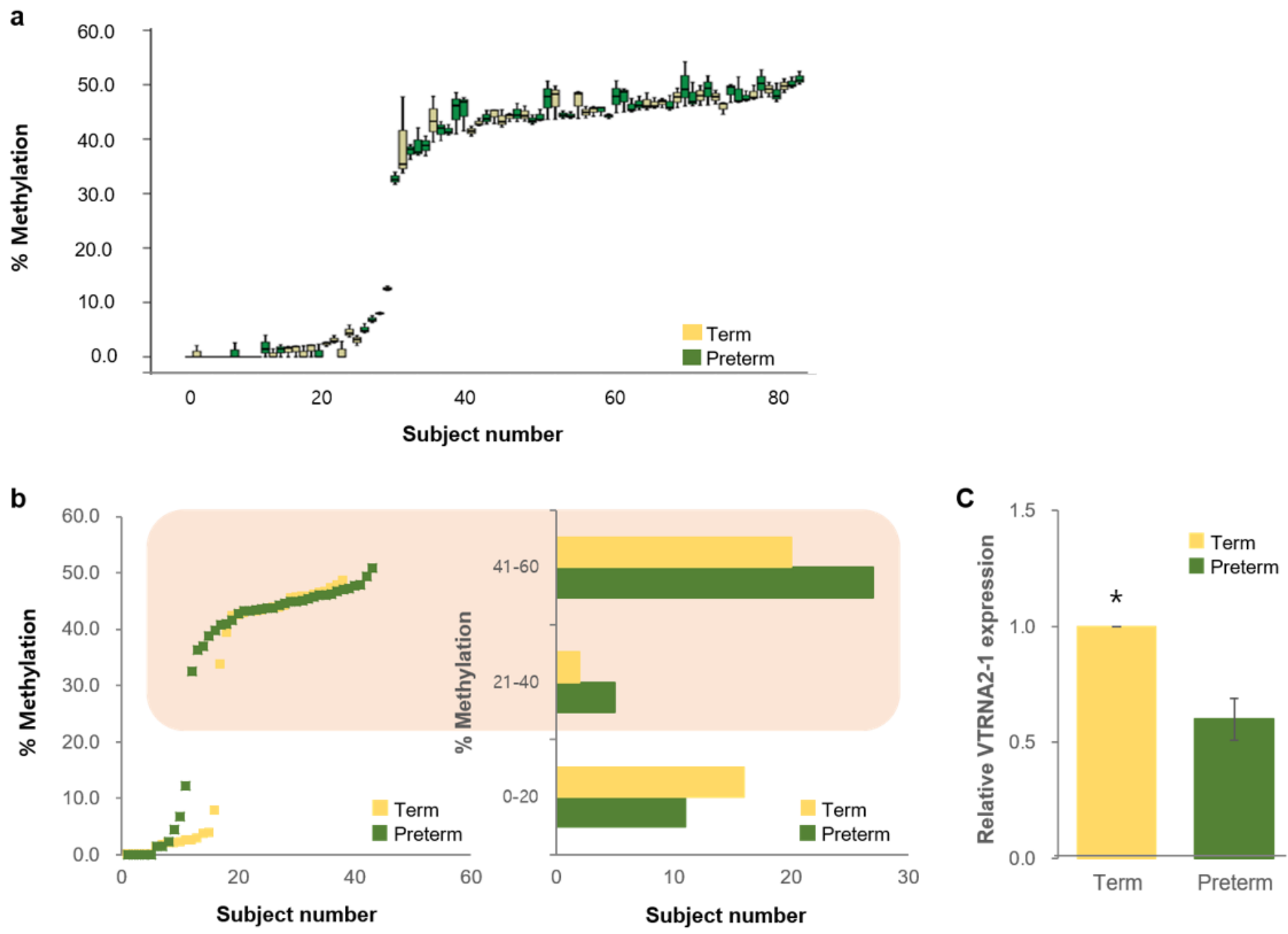

Figure 1

Methylation differences in VTRNA2-1 between term and preterm samples. (a) Rank plot of three methylated sites on VTRNA21 by bisulphite pyrosequencing. (b) Bisulphite pyrosequencing data of 82 Korean pregnant women with term and preterm deliveries. The rank plot (left) highlights the different distributions. The histogram (right) shows the distribution of term and preterm deliveries according to the VTRNA2-1 methylation level. (c) Relative expression levels of VTRAN2-1 in maternal blood (term, $n=20$; preterm, $n=20$ ).

\section{Supplementary Files}

This is a list of supplementary files associated with this preprint. Click to download.

- STablesandFigures.docx

- STable1.xIsx 